\title{
Erratum on: Insights from the supplementary motor area syndrome in balancing movement initiation and inhibition
}

\section{Frontiers Production Office * \\ Frontiers Production Office, Frontiers, Switzerland \\ ${ }^{*}$ Correspondence: production.office@frontiersin.org}

\section{Approved by:}

Neuroscience Editorial Office, Frontiers, Switzerland

Keywords: supplementary motor area (SMA), supplementary motor area syndrome, akinetic mutism, neurosurgery, Parkinson's disease, tic disorders

\section{An erratum on}

Insights from the supplementary motor area syndrome in balancing movement initiation and inhibition

by Potgieser, A. R. E., de Jong, B. M., Wagemakers, M., Hoving, E. W., and Groen, R. J. M. (2014) Front. Hum. Neurosci. 8:960. doi: 10.3389/fnhum.2014.00960

Reason for Erratum:

The first sentence of Figure 1 caption was applied to Figure 2 caption along with the footnote that was supposed to be in the caption for Figure 1, due to a typesetting error. This error does not change the scientific conclusions of the article in any way. The publisher apologizes for this error and the correct version of both Figures 1, 2 with their corrected captions appears below.

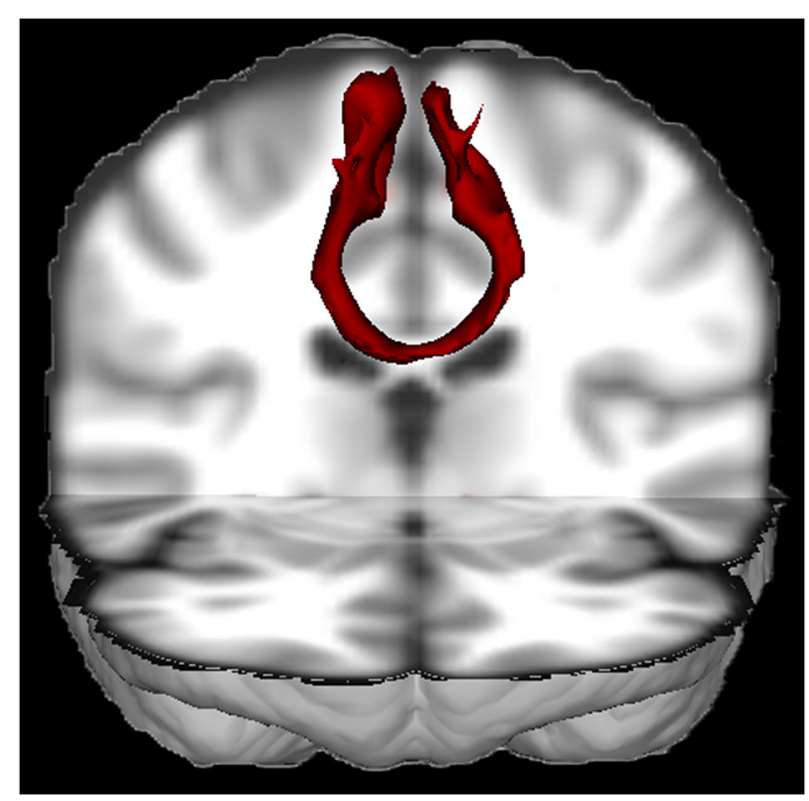

FIGURE 1 | 3D view of the probabilistic tractography between both SMA's from a single healthy subject (made with FSL) ${ }^{1}$. The tractography result was transformed to Montreal Neurological Institute (MNI) space. This figure nicely illustrates that the SMA's are densely interconnected through the corpus callosum.

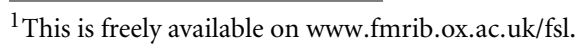

Received: 09 January 2015; accepted: 09 January 2015; published online: 22 January 2015.

Citation: Frontiers Production Office (2015) Erratum on: Insights from the supplementary motor area syndrome in balancing movement initiation and inhibition. Front. Hum. Neurosci. 9:19. doi: 10.3389/fnhum.2015.00019

This article was submitted to the journal Frontiers in Human Neuroscience.

Copyright (C) 2015 Frontiers Production Office. This is an open-access article dis tributed under the terms of the Creative Commons Attribution License (CC BY). The use, distribution or reproduction in other forums is permitted, provided the original author(s) or licensor are credited and that the original publication in this journal is cited, in accordance with accepted academic practice. No use, distribution or reproduction is permitted which does not comply with these terms.

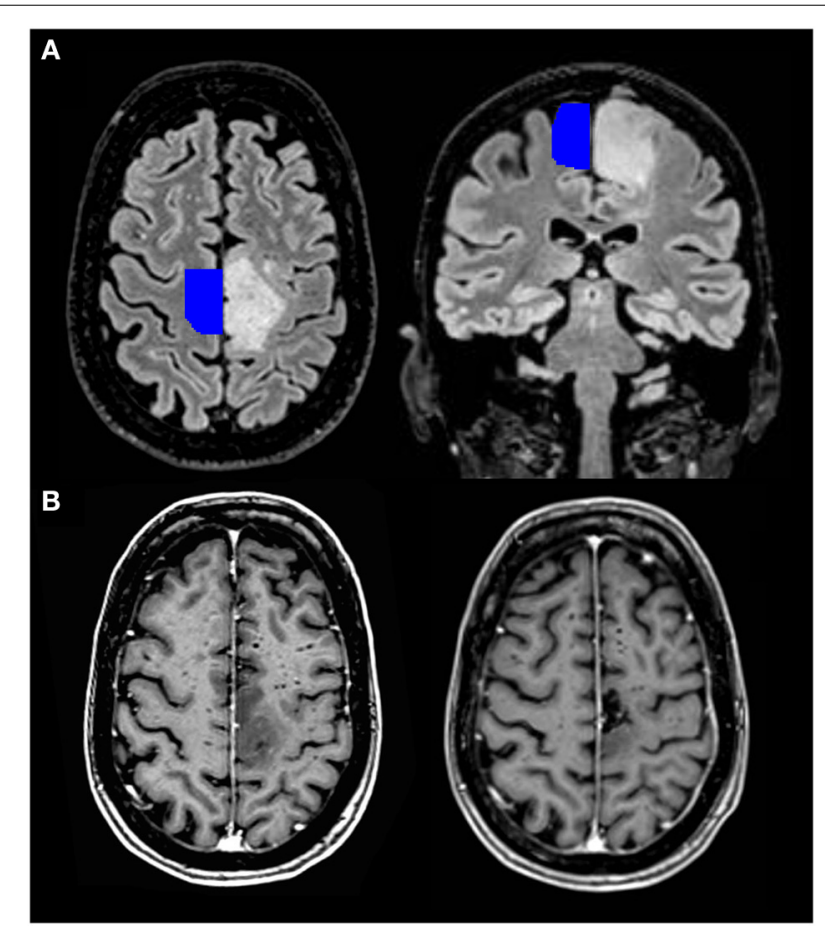

FIGURE 2 | Pre- and post-operative MRI scan of a 64-year-old patient with a diffuse astrocytoma (WHO grade II) in the left SMA. (A) Transversal and coronal T2-weighted FLAIR images, with an SMA template projected on the healthy hemisphere. The latter is freely available and derived from a large meta-analysis describing the location of the sensorimotor areas (Mayka et al., 2006). (B) Transversal images after gadolinium contrast from the same patient before (left lower corner) and three months after the operation (right lower corner). She had a complete motor loss on the right side after the operation, which quickly recovered. 